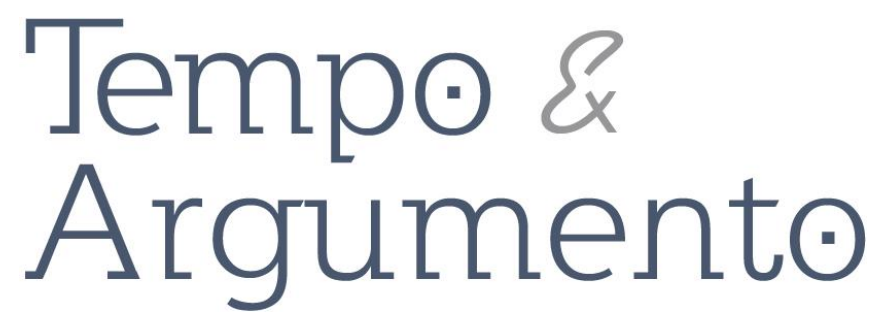

\title{
Frozen empires
}

\section{Resenha da obra:}

HOWKINS, Adrian. Frozen empires: an environmental history of the Antarctic Peninsula. New York, NY: Oxford University Press, 2017.

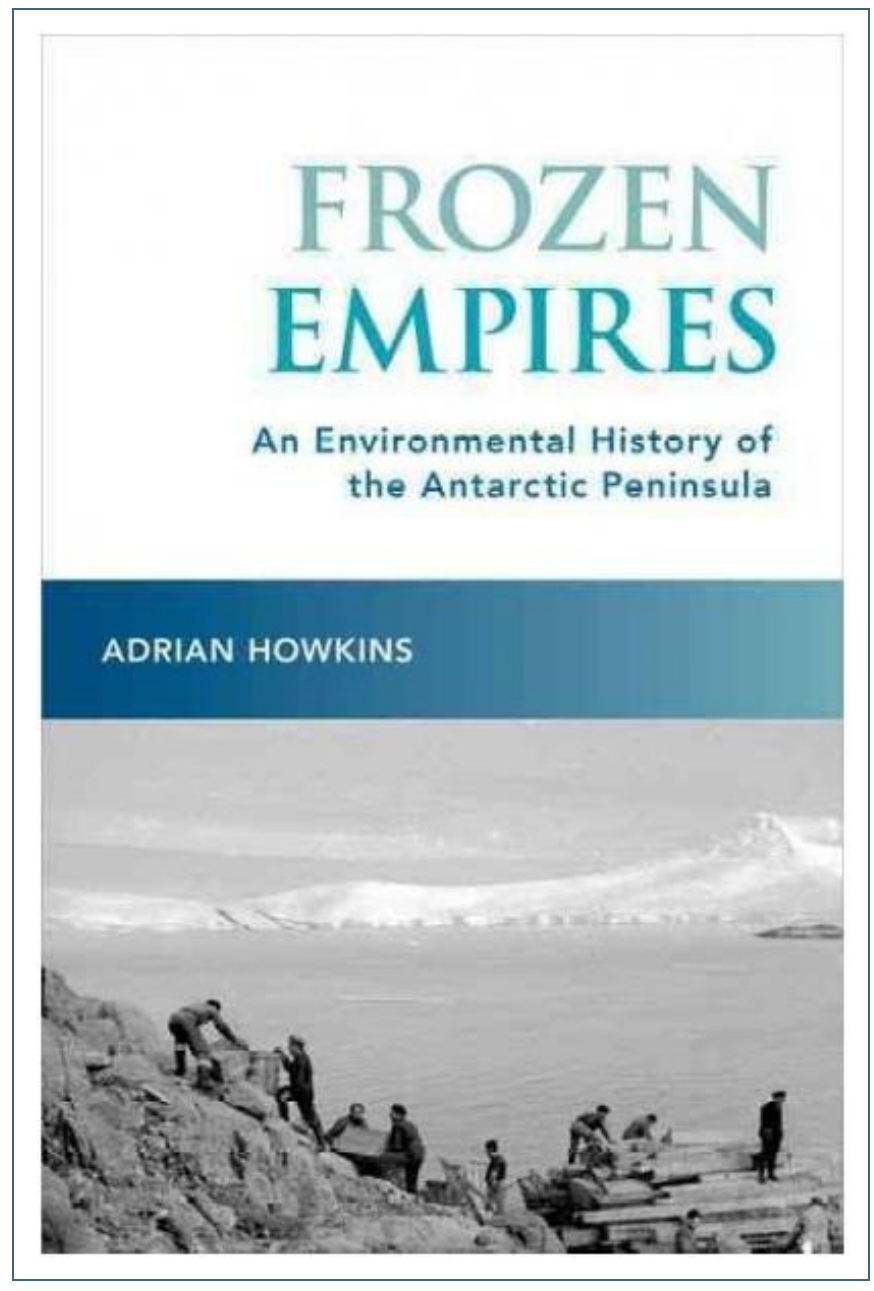

Autor da resenha

\section{Hermes Andrade Júnior}

Bacharel em Relações Internacionais. Doutor (D. Sc.) pela Escola Nacional de Saúde Pública (FIOCRUZ). Pós-Doutorado na Universidade Católica Portuguesa (UC/FFCS/CEFH). Braga - PORTUGAL orcid.org/0000-0002-3667-1354 handradejunior@gmail.com

\section{Para citar esta resenha:}

HOWKINS, Adrian. Frozen empires: an environmental history of the Antarctic Peninsula. New York, NY: Oxford University Press, 2017. Resenha de: ANDRADE JÚNIOR, Hermes. Frozen empires. Revista Tempo e Argumento, Florianópolis, v. 11, n. 26, p. 616 - 622. jan./abr. 2019.

\section{DOI: $10.5965 / 2175180310262019616$}

http://dx.doi.org/10.5965/2175180310262019616 
O continente da Antártida é desconhecido pelas pessoas comuns e pela maioria da comunidade científica. Apenas uma plêiade de pesquisadores, militares, exploradores e aventureiros que agem com objetivos muito específicos conhece as microrrealidades de somente parte do continente, notadamente as áreas de exploração, de comércio, dos pontos de parada e descanso e dos estudos continuados em um lugar onde a natureza é exigente e inóspita para os seres humanos. Esses contrastes trazem muita curiosidade, pois ainda parece ser uma região pouco conquistada, mas não pouco disputada, e essa é a versão deste livro.

O livro em si é um estudo de caso de confluência da macropolítica internacional, especialmente dotada em termos geopolíticos, e com nexos explicativos de fundo ambiental, ou seja, com uso da ciência ambiental. Assume características de um discurso ambiental e geofísico com aparato científico de suporte, sempre amparado por militares estrategistas de todas as nações interessadas na disputa por seu território. O autor, Adrian Howkins, é professor e pesquisador de História na Universidade Estadual do Colorado, EUA.

Mas, por que tanto interesse na região já que é perpetuamente coberta de gelo e neve e sem habitantes nativos? A montanhosa Península Antártica que se estende para o sul em direção ao Polo Sul e que se funde com a maior e mais fria massa de gelo do planeta é, mesmo assim, a região apontada pelo autor como a que tem a história política mais contestada de qualquer parte do Continente Antártico.

O lado ocidental da península provou ser a parte mais acessível da região, como resultado das correntes oceânicas e ventos que mantêm o mar relativamente livre de gelo durante os verões e onde confluem todas as reivindicações de soberania e de sobreposição. Para o leste, onde as reivindicações da Argentina e da Grã-Bretanha, mas não do Chile, se sobrepõem, a região politicamente definida da Península Antártica se estende pelo Mar de Weddell e inclui as plataformas de gelo e gelo ao sul. Para o norte, a região da Península Antártica inclui as Ilhas Shetland do Sul, que são reivindicadas pelos três países, com as Ilhas Órcades do Sul, Ilhas Sandwich do Sul e Geórgia do Sul, que são disputadas pela Grã-Bretanha e Argentina.

É importante salientar que o autor centrou seu estudo na Península Antártica e não no todo do continente da Antártida. Isso, metodologicamente sustenta seu estudo 
de caso na fluência do exame das evidências, mas também deixa claro que nações (que algumas o autor também categoriza como impérios) tinham a pretensão somente na Península Antártica ou no continente como um todo, afirmando seus interesses enquanto atores de forma explícita em um ou outro território ou na extensão de continuidade de seus territórios.

Howkins sinaliza que nas décadas de 1920 e 1930, por exemplo, os britânicos usaram as "investigações de descoberta" (p.8) biológicas marinhas para produzir informações sobre as baleias que poderiam ser usadas para regular a indústria baleeira de maneira sustentável e, nas décadas intermediárias do século XX, fizeram um uso cada vez mais sistemático de levantamentos e mapeamentos para afirmar seu controle sobre as dependências das Ilhas Falkland.

Assim, desde o início do século XX, Argentina, Grã-Bretanha e Chile fizeram reivindicações de soberania sobrepostas, enquanto os Estados Unidos (a Doutrina Hughes de 1924 se recusou a reconhecer quaisquer reivindicações de soberania à Antártida e, ao mesmo tempo, reservou os direitos dos EUA a qualquer parte do continente) e a Rússia reservaram direitos para todo o continente.

A ameaça de um confronto armado entre a Grã-Bretanha, a Argentina e o Chile era uma grande preocupação para os formuladores de políticas dos EUA, já que os três países eram importantes aliados da Guerra Fria e qualquer conflito entre eles seria bom para a União Soviética. Como consequência, os Estados Unidos assumiram a liderança na promoção de vários planos para trazer uma solução pacífica para a disputa de soberania na região da Península Antártica. Ao procurar equilibrar os objetivos conflitantes de promover seus próprios interesses e promover a paz, os Estados Unidos tentaram avaliar o valor econômico do continente.

No fenômeno deste caso, o tema do meio ambiente está no centro dessas disputas pela soberania, colocando a Península Antártica como cruzamento da história das relações internacionais e da história ambiental na região. Sobre a importância de estudá-lo, estações de exploração científica, segundo Howkins, serviram de fachada e de cobertura aos argumentos para as afirmações de soberania em várias cimeiras, com episódios de confrontações militares abertas, como no Caso das Malvinas/Falklands, que 
foram vividos diretamente pelo cenário de disputa construído com tais precedentes históricos.

A narrativa apresentada por Adrian Howkins é muito bem escrita e amparada em vigorosas fontes documentais e testemunhais, como um digno trabalho de campo aprofundado para obter um estudo de caso consistente. Munido de fartos documentos catalogados cuidadosamente, fatos e registros históricos bem interpretados, o autor afirma que tem havido uma continuidade fundamental nos modos pelos quais as potências imperiais usaram assuntos do meio ambiente para apoiar suas reivindicações políticas na região da Península Antártica e que essas múltiplas reivindicações e afirmações de direitos que se sobrepunham tornaram a Península Antártica uma das regiões mais disputadas em qualquer lugar do planeta.

Nos jogos de poder, os britânicos, pelo lado dos colonizadores, argumentaram que a produção de conhecimento científico útil sobre a Antártica os ajudou a justificar a sua posse e do outro lado, em tentativa de emancipação, a Argentina e o Chile argumentavam que a Península Antártica pertencia a eles como resultado da proximidade geográfica, da continuidade geológica e de um senso geral de conexão. No entanto, como resultado, apesar dos vários desafios e reivindicações, o autor afirma que nunca houve uma genuína descolonização da região da Península Antártica.

Em vez disso, as afirmações britânicas de que as respectivas entidades estavam conduzindo a ciência "para o bem da humanidade" (p. 8, 21) foram reformuladas pelos termos do Tratado Antártico de 1959 e os "impérios congelados" (p. 16-22) da Antártica, assim denominados pelo autor (o tratado "congelou" (p.21) todas as reivindicações de soberania e reservas de direitos à Antártida, nem as reconhecendo nem as rejeitando), permanecem até hoje no mesmo status.

$\mathrm{Na}$ justaposição da aparente hostilidade do ambiente material da Península Antártica com a disputada história política da região, são levantadas uma série de questões. Por que o ambiente aparentemente sem valor e hostil da região da Península Antártica se tornou tão contestado ao longo do século XX? Que papel o ambiente desempenhou na forma como esses conflitos políticos se desenvolveram? E quais foram os resultados e implicações deste conflito? 
O recrudescimento das hostilidades depois do rompimento da "coexistência pacífica" intensificou-se no curioso caso chamado de tentativa de descolonização, uma vez que as pretensões do Chile e da Argentina foram abertamente discutidas em ambiente de Guerra Fria, cercado pela mega influência bipolar do mundo EUA-URSS, que obviamente decidiram manter seus interesses no continente antártico e não somente na Península Antártica.

Confirma-se uma história ambiental da descolonização no gelo no continente (PYNE, 2003). No panorama da obra, verificam-se grandes categorias de reinvindicação históricas e historicizantes. Em primeiro lugar, a geopolítica do conhecimento para gerar soberania a ser usada como estratégia dos colonizadores (internacionalismo científico) e, em segundo lugar, o nacionalismo ambiental dos colonizados.

Exemplificando, o interesse argentino e chileno na região desafiava não apenas a posse britânica das dependências das Ilhas Malvinas, mas também a conexão imperial entre o conhecimento ambiental e o poder político. Por um tempo, pelo menos, esse “nacionalismo ambiental” sul-americano (p. 59-82) produziu visões do ambiente antártico que diferiam significativamente do foco da Grã-Bretanha na ciência. Apesar do seu afastamento, a história do conflito entre o imperialismo britânico e o nacionalismo sulamericano na região da Península Antártica conecta-se com a história mais ampla da descolonização de meados do século XX.

Em $1^{\circ}$ de dezembro de 1959, doze nações - incluindo Grã-Bretanha, Argentina, Chile, Estados Unidos e União Soviética - assinaram o Tratado da Antártida, que suspendeu todas as reivindicações de soberania e reservas de direitos, e criou um continente dedicado à paz e à ciência. Interpretações tradicionais consideraram o tratado como um importante ponto de virada na história antártica, encerrando em grande parte as lutas políticas do continente e implementando uma nova era do internacionalismo científico, mas também há que se considerar outros focos interpretativos, uma vez que "a ausência de estruturas administrativas formais deixou a natureza jurídica do Tratado da Antártida deliberadamente vaga" (p. 161).

Howkins aplica uma perspectiva mais ampla da história ambiental da região da Península Antártica que sugere que a Antártida continua a ser um ambiente imperial, com a ciência continuando a ser usada para legitimar o poder político. Embora a assinatura do 
Tratado certamente tenha marcado o declínio do nacionalismo ambiental sul-americano, ele não mudou significativamente a política imperial subjacente do continente. E, embora o Chile e a Argentina nunca tenham desistido de proclamar seus direitos territoriais à região da Península Antártica, eles começaram a aceitar a conexão entre ciência e poder político e abandonaram em grande medida o nacionalismo ambiental das décadas de 1930, 1940 e 1950. Desde a sua ratificação em 1961, o envolvimento da Argentina e do Chile se mostrou importante na defesa do Tratado da Antártida de acusações de exclusividade. Fica a lembrança de que a conexão entre ciência e soberania usada pela Grã-Bretanha para justificar suas reivindicações às dependências das Ilhas Malvinas foi criticada pelo nacionalismo ambiental que, ao invés de competir com as mesmas armas que não estariam disponíveis, procurou outras formas não científicas de usar o ambiente antártico para promover a propriedade.

Na sua explanação, o autor prova que novas descobertas eram frequentemente feitas na península, sendo nomeadas e descritas por expedições imperiais, com poucas narrativas concorrentes. Com o tempo, com a construção de estações de pesquisa britânicas e através de vários esquemas para desenvolver o ambiente antártico, as percepções da região da Península Antártica como um ambiente imperial contribuíram para moldar sua realidade material. Certamente havia limitações às afirmações britânicas de autoridade ambiental e à construção da região da Península Antártica como um ambiente imperial. As pretensões britânicas de entender, simplificar e controlar a Antártida poderiam frequentemente parecer ridículas em face da vastidão da região e de sua hostilidade à presença de seres humanos e seus mares congelados, fendas, tempestades e maremotos. Nos dias de hoje, as afirmações britânicas de autoridade ambiental mostraram-se poderosas na construção da região da Península Antártica como um ambiente imperial. Nomes de lugares britânicos continuam a ser usados; a ciência tornou-se uma atividade normativa e é difícil pensar na região sem alguma referência às expedições científicas do início do século XX.

Em sua conclusão, o autor afirma que, infelizmente, para o nacionalismo ambiental chileno e argentino, os dois países sul-americanos nunca chegaram a um acordo sobre quem detinha o quê no continente sulista. Como consequência, o desafio ao imperialismo britânico foi significativamente enfraquecido. É interessante especular o que poderia ter 
acontecido com a história da região da Península Antártica se o Chile e a Argentina tivessem chegado a um acordo sobre suas respectivas reivindicações; isso, no mínimo, teria dado a outros países simpáticos à sua causa anti-imperial algo a reconhecer. No entanto, os diplomatas chilenos e argentinos se viram gastando quase tanto tempo competindo entre si em reivindicações, lutando contra o imperialismo britânico.

Mais amplamente ainda, traz uma reflexão final de que o argumento para a continuidade imperial na história ambiental da região da Península Antártica poderia ser usado como modelo para pensar sobre as políticas ambientais de outras partes do mundo, especialmente em lugares diretamente influenciados pelas histórias do imperialismo europeu e da descolonização.

Afirmações da autoridade ambiental podem ser vistas como uma poderosa ferramenta política em muitas questões importantes, em muitas partes do mundo, e este livro provou isso. É leitura recomendada para todos os que querem ter contato com parte pouco conhecida do Atlântico Sul e do continente antártico, em especial no que tange aos países latino-americanos do Mercosul como o Brasil, que viveu, mesmo na neutralidade da Guerra das Malvinas em 1982, o drama de ter mais uma guerra como dilema das relações internacionais de seus vizinhos, agora parceiros estratégicos.

\section{Referências}

HOWKINS, Adrian. Frozen empires: an environmental history of the Antarctic Peninsula. New York, NY: Oxford University Press, 2017.

PYNE, Stephen J. The Ice. London: Weidenfeld \& Nicolson, 2003.

Recebido em 20/08/2018 Aprovado em 18/10/2018

Universidade do Estado de Santa Catarina - UDESC Programa de Pós-Graduação em História - PPGH Revista Tempo e Argumento Volume 11 - Número 26 - Ano 2019 tempoeargumento@gmail.com 